\section{Regarding the Use of Epinephrine Auto-injectors in Remote Settings}

To the Editor:

We read with interest the recent article by Hawkins et al, ${ }^{1}$ entitled "Retrieval of additional epinephrine from auto-injectors." The EpiPen and EpiPen Jr auto-injectors are distributed by Mylan Specialty L.P., formerly known as Dey Pharma. The company wishes to clarify a few statements in the article that are outdated or outside of product labeling approved by the US Food and Drug Administration (FDA).

EpiPen and EpiPen Jr are labeled for single use only, ${ }^{2}$ and Mylan does not condone their use for multiple dosing. Consequently, the company does not sanction the procedures described in the article by Hawkins et al. ${ }^{1}$ Mylan is aware that epinephrine may remain in the autoinjector after use owing to product over-fill to deliver the labeled doses of $0.3 \mathrm{mg}$ for EpiPen or $0.15 \mathrm{mg}$ for EpiPen $\mathrm{Jr}^{2}$

Consistent with the approved product label, Mylan also recommends regular inspection of the epinephrine solution for visual changes. ${ }^{2}$ If the solution contains particulate matter or takes on a pinkish or brown color, EpiPen or EpiPen Jr should be replaced immediately because efficacy may have been compromised. Patients should also remember that epinephrine is light sensitive, and EpiPen or EpiPen $\mathrm{Jr}$ should be stored in the carrier tube provided and at temperatures ranging from $20^{\circ} \mathrm{C}$ to $25^{\circ} \mathrm{C}\left(68^{\circ} \mathrm{F}\right.$ to $\left.77^{\circ} \mathrm{F}\right)$; excursions are permitted to $15^{\circ} \mathrm{C}$ to $30^{\circ} \mathrm{C}\left(59^{\circ} \mathrm{F}\right.$ to $86^{\circ} \mathrm{F}$ ).

For further information about the proper use and storage of EpiPen or EpiPen Jr auto-injectors, the FDA-approved product labeling is available at www. epipen.com.

Ray A. Wolf, PharmD Medical Director, Medical Affairs Mylan Specialty L.P. Canonsburg, $P A$

\section{References}

1. Hawkins SC, Weil C, Baty F, Fitzpatrick D, Rowell B. Retrieval of additional epinephrine from auto-injectors. Wilderness Environ Med. 2013;24:434-444.

2. EpiPen (epinephrine) auto-injector $0.3 \mathrm{mg}$ and EpiPen $\mathrm{Jr}$ (epinephrine) auto-injector $0.15 \mathrm{mg}$ [prescribing information]. Basking Ridge, NJ: Mylan Specialty L.P.; 2012 .

\section{A Novel Risk Factor for High Altitude Pulmonary Edema?}

To the Editor:

I write to report the occurrence of high altitude pulmonary edema (HAPE) in a previously nonsusceptible woman after a total abdominal hysterectomy and bilateral salpingo-oophorectomy (TAH-BSO), suggesting another potential risk factor-ovarian hormone deficiency-that warrants further investigation as a factor affecting pulmonary vascular and ventilatory responses to hypoxia in humans and, potentially, the risk of HAPE.

A 44-year-old woman planned to climb Denali (6195 m) with a guided expedition in the spring of 2013. After spending 1 night at base camp $(2195 \mathrm{~m})$, she spent 2 nights at $2380 \mathrm{~m}$, including establishing a supply cache at $3050 \mathrm{~m}$, before ascending to $3350 \mathrm{~m}$. On the first day at this elevation, she traveled to and from the supply cache at $3050 \mathrm{~m}$ without difficulty. That evening she awoke with "gurgling in her chest." Upon evaluation by the guide the next morning, her oxygen saturation $\left(\mathrm{Spo}_{2}\right)$ was $86 \%$ to $87 \%$ at rest and $70 \%$ with ambulation. Pulse oximetry checks at rest the remainder of the day revealed $\mathrm{SpO}_{2}$ of $82 \%$ to $86 \%$. She noted difficulty walking slightly uphill in the evening. The next morning, she had severe dyspnea while ascending Motorcycle Hill, could not keep up with her team, and returned to camp, where she noted cough productive of blood-tinged sputum and had resting $\mathrm{SpO}_{2}$ in the low to mid $70 \%$ range. She was evaluated by the Denali Ranger Patrol and was told she had crackles in both lungs (an official Patrol report is not available). After 6 hours at camp, she was escorted on foot to base camp. She noted difficulty keeping up with the group and moved slowly on the uphill section leading to base camp. She was flown by plane to Talkeetna (elevation $100 \mathrm{~m}$ ) where her symptoms resolved. A subsequent evaluation in Seattle, Washington, which did not include chest radiography, revealed no cardiopulmonary abnormalities.

Before her climb, she had no respiratory, cardiac, or endocrine disorders. One month before the climb, she had a bicycle accident resulting in a concussion, separated shoulder, and lip laceration that became infected and required antibiotics. Chest radiography at that time was normal. In 2011, she underwent prophylactic TAHBSO after being found to have the BRCA-2 mutation, and in 2012, underwent bilateral mastectomy for stage 0 breast cancer. Her only medication during the climb was gabapentin for hot flashes. She was not taking estrogen replacement therapy. She had no history of altitude illness during previous high altitude climbs, including 
two 3-day ascents of Mount Rainier (4393 m) and ascents of Kilimanjaro (5895 m), Iztaccihuati $(5285 \mathrm{~m})$, and Orizaba $(5638 \mathrm{~m})$. Except for 1 Mount Rainier ascent, all of these climbs occurred before her surgeries in 2011 and 2012.

Without formal records from the Denali Ranger Patrol evaluation at $3350 \mathrm{~m}$, it is difficult to confirm that she met the Lake Louise criteria for HAPE, but the presence of severe dyspnea on exertion, an $\mathrm{SpO}_{2}$ lower than expected for that elevation that worsened with exertion, cough with blood-tinged sputum, and improvement with descent are consistent with this diagnosis. Given the absence of fever, purulent sputum production, and pleuritic chest pain and the subacute onset of symptoms, diagnoses such as pneumonia or pulmonary embolism are less likely.

A noteworthy feature of this case is that she never had HAPE on previous climbing trips that involved spending several days at elevations greater than the elevation at which she became sick on Denali. Importantly, with the exception of 1 summit of Mount Rainier, all of her high altitude climbing expeditions occurred before her TAHBSO in 2011. With no history of endocrinopathy, she likely had normal estrogen and progesterone levels on the majority of those earlier climbs but not on the Denali expedition.

A definitive link cannot be proved, but several lines of evidence suggest that changes in the endogenous ovarian hormone levels may have affected this woman's susceptibility to HAPE on Denali. HAPE occurs as the result of excessive hypoxic pulmonary vasoconstriction (HPV) and a large rise in pulmonary artery pressure, ${ }^{1,2}$ and HAPE susceptible persons demonstrate markedly increased pulmonary vascular responses to hypoxia at rest and with exercise. ${ }^{3}$

Although the effect of estrogen on HPV has not been studied in humans, animal data demonstrate that estrogen blunts both acute and chronic pulmonary vascular responses to hypoxia. ${ }^{4}$ Lahm et $\mathrm{al}^{5}$ demonstrated that high doses of exogenous $17 \beta$-estradiol rapidly decreased hypoxic pulmonary vasoconstriction in rats in a dosedependent manner. Similarly, $\mathrm{Xu}$ et $\mathrm{al}^{6}$ exposed rats to hypobaric hypoxia $\left(\mathrm{P}_{\mathrm{B}} 380 \mathrm{~mm} \mathrm{Hg}\right)$ for 21 days and noted less severe hypoxia-induced pulmonary hypertension in rats with higher serum estradiol levels. The precise mechanism is not clear but may relate to increased prostacyclin release, upregulation of endothelial nitric oxide synthase, and downregulation of endothelin-1 expression. ${ }^{4}$

In addition to a direct effect of estrogen on HPV, decreased endogenous estrogen and progesterone may blunt ventilatory responses to hypoxia, which, in turn, could decrease alveolar oxygen tensions and enhance
HPV. Animal models demonstrate decreased carotid sinus nerve activity and decreased ventilatory responses in hypoxia after oophorectomy, ${ }^{7}$ as well as enhanced ventilatory responses to hypoxia after administration of estrogen and progesterone. ${ }^{8}$ Women have also been shown to have higher ventilatory responses in the luteal phase of the menstrual cycle than in the follicular phase when estrogen levels decline, ${ }^{9}$ and studies from South America demonstrate evidence of lower alveolar ventilation in postmenopausal women than in premenopausal women. ${ }^{10}$

Taken together, this indirect evidence suggests ovarian hormone deficiency may have affected the patient's susceptibility to HAPE. The absence of estrogen may have enhanced HPV when compared to prior expeditions at high altitude, while the absence of estrogen and progesterone may have blunted ventilatory responses to hypoxia, leading to lower alveolar ventilation and oxygen tensions and a stronger stimulus for HPV.

A final piece of evidence that lends credence to this hypothesis is the possible male predominance of the disorder in multiple series of HAPE patients. ${ }^{11-13}$ These observational data do not prove a causal link, however, and the fact that only $20 \%$ of the affected women in the series by Hultgren et $\mathrm{al}^{11}$ were more than 50 years of age and past menopause suggest that other factors beside ovarian hormone levels contributed to the observed sex differences.

In considering the possible link between ovarian hormone deficiency and HAPE in this case, it should be noted that one of the patient's high altitude ascents occurred after her TAH-BSO. During her second ascent of Mount Rainier, she spent 1 night at $3080 \mathrm{~m}$ and a second night at $3380 \mathrm{~m}$ before summiting and then descending to the trailhead. However, HAPE is usually seen 2 to 5 days after ascent to high elevation, and the time spent above $3350 \mathrm{~m}$ during her Rainier climb was shorter than the time she spent at that elevation on Denali. In addition, owing to the lack of porter support and the amount of supplies carried by climbing parties, Denali ascents involved more physical exertion than her other climbs, which, given the effect of exertion on pulmonary artery pressure, may have affected her susceptibility on this particular expedition compared to her earlier ones. Finally, the patient did have an infection before her climb, and preceding inflammatory processes have been suggested as a possible risk for HAPE, ${ }^{14}$ but the location of her infection outside the respiratory tract and timing relative to her climb make this less likely.

This case does not prove a role for ovarian hormone deficiency in the pathogenesis of HAPE but does suggest alternative areas of research into pulmonary vascular responses to hypoxia and risk factors for this disease. For 
example, it is feasible to measure pulmonary artery pressure responses to hypoxia in premenopausal women before and after elective oophorectomy. One could also assess pulmonary artery pressure responses to hypoxia in postmenopausal women both before and after a short course of estrogen or progesterone, or both. Finally, it may be possible to do a retrospective cross-sectional analysis of a registry of HAPE patients to see if there is a relationship between postmenopausal status and risk for HAPE.

This case should also not be viewed as reason to administer estrogen or progesterone to postmenopausal women or to those who have undergone oophorectomy for HAPE prevention. Instead, women with and women without a prior history of HAPE should continue to follow current guidelines for HAPE prophylaxis with future ascents.

Andrew M. Luks, MD Division of Pulmonary and Critical Care Medicine Department of Medicine University of Washington and Harborview Medical Center Seattle, WA

\section{References}

1. Maggiorini M, Melot C, Pierre S, et al. High-altitude pulmonary edema is initially caused by an increase in capillary pressure. Circulation. 2001;103:2078-2083.

2. Swenson ER, Maggiorini M, Mongovin S, et al. Pathogenesis of high-altitude pulmonary edema: inflammation is not an etiologic factor. JAMA. 2002;287:2228-2235.

3. Dehnert C, Grunig E, Mereles D, von Lennep N, Bartsch P. Identification of individuals susceptible to high-altitude pulmonary oedema at low altitude. Eur Respir J. 2005;25: 545-551.

4. Lahm T, Crisostomo PR, Markel TA, et al. The effects of estrogen on pulmonary artery vasoreactivity and hypoxic pulmonary vasoconstriction: potential new clinical implications for an old hormone. Crit Care Med. 2008;36:2174-2183.

5. Lahm T, Crisostomo PR, Markel TA, et al. Exogenous estrogen rapidly attenuates pulmonary artery vasoreactivity and acute hypoxic pulmonary vasoconstriction. Shock. 2008;30:660-667.

6. Xu D, Niu W, Luo Y, et al. Endogenous estrogen attenuates hypoxia-induced pulmonary hypertension by inhibiting pulmonary arterial vasoconstriction and pulmonary arterial smooth muscle cells proliferation. Int $J$ Med Sci. 2013;10:771-781.

7. Tatsumi K, Pickett CK, Jacoby CR, Weil JV, Moore LG. Role of endogenous female hormones in hypoxic chemosensitivity. J Appl Physiol (1985). 1997;83:1706-1710.
8. Hannhart B, Pickett CK, Moore LG. Effects of estrogen and progesterone on carotid body neural output responsiveness to hypoxia. J Appl Physiol (1985). 1990;68:1909-1916.

9. White DP, Douglas NJ, Pickett CK, Weil JV, Zwillich CW. Sexual influence on the control of breathing. J Appl Physiol Respir Environ Exerc Physiol. 1983;54: 874-879.

10. Leon-Velarde F, Rivera-Chira M, Tapia R, Huicho L, Monge CC. Relationship of ovarian hormones to hypoxemia in women residents of 4,300 m. Am J Physiol Regul Integr Comp Physiol. 2001;280:R488-R493.

11. Hultgren HN, Honigman B, Theis MK, Nicholas D. Highaltitude pulmonary edema at a ski resort. West $\mathrm{J}$ Med. 1996;164:222-227.

12. Sophocles AM, Bachman J. High-altitude pulmonary edema among visitors to Summit County, Colorado. J Fam Pract. 1983;17:1015-1017.

13. Jones BE, Stokes S, McKenzie S, Nilles E, Stoddard GJ. Management of high altitude pulmonary edema in the Himalaya: a review of 56 cases presenting at Pheriche medical aid post $(4240 \mathrm{~m})$. Wilderness Environ Med. 2013;24:32-36.

14. Durmowicz AG, Noordeweir E, Nicholas R, Reeves JT. Inflammatory processes may predispose children to highaltitude pulmonary edema. J Pediatr. 1997;130:838-840.

\section{Is Drinking to Thirst a Prudent Guideline to Avoid Hyponatremia?}

\section{To the Editor:}

I would like to address a statement made in the recent article on treatment of exercise-associated hyponatremia by Bennett et al. ${ }^{1}$ The statement "...prudent guidelines include drinking to thirst.." is a questionable and perhaps dangerous suggestion.

In exertional activities, thirst is the signal that your body is in the first stages of dehydration, ${ }^{2}$ and after 40 years of managing extensive outdoor programs I have found it is a major issue to get participants to drink sufficient quantities of liquid to stay adequately hydrated and healthy. If all outdoor sojourners continually waited to drink until they were thirsty, I suspect there would be a significant increase in heat and dehydration injuries and altitude problems, which would far outpace the hyponatremia spectrum.

As a former international mountain/travel guide, Outward Bound program manager, senior SOLO Wilderness Medicine staff member (30 years), and Wilderness Medical Society member and presenter (22 years), I have some comments for our membership.

For those of us who have taken participants to the far corners of the Earth, keeping them safe and healthy is our first priority. On such journeys, preventing 